\title{
Properties and Applications of the Electrohydraulic Servosystem of the Hydraulic Excavator
}

\author{
W. H. Jia, ${ }^{a, 1}$ C. B. Yin, ${ }^{b}$ G. Li, ${ }^{a}$ C. L. Sun, ${ }^{a}$ C. Wang, ${ }^{a}$ and H. Feng ${ }^{b}$ \\ ${ }^{a}$ School of Mechanical Engineering, Nanjing Institute of Technology, Jiangsu, China \\ ${ }^{\mathrm{b}}$ School of Mechanical and Power Engineering, Nanjing University of Technology, Jiangsu, China \\ 1'geovrml@163.com
}

The service of a hydraulic excavator is complicated by poor environment. The safety and stability of the control system are influenced by external factors. The object of the study is the electrohydraulic servosystem of the hydraulic excavator. The mathematical and simulation models using AMESIM for the servosystem are constructed. Then the pressure and flow characteristics are analyzed. The design and optimization of the electrohydraulic servosystem and its application in excavator engineering are described. The operation process is graphically presented by a curve, which steeply slopes up (rising period) and then flattens out (stabilization period), those periods are shortened by 38.0 and 40.5\%, respectively, the delay tracking period decreased by $52.6 \%$, and anti-interference is reliable.

Keywords: electrohydraulic system, delay tracking period, anti-interference, safety and stability.

Introduction. As a key part of engineering machinery, hydraulic excavators have been widely used in construction, transportation, and disaster rescue operations, due to their superior efficiency. However, the complicated working conditions and harsh working environment of hydraulic excavators have proposed higher requirements for their intelligent control. By combining hydraulic and electrical control technologies, the electrohydraulic servosystem facilitates hydraulic excavators [1-3] in remote control, self-operation, and synergetic work via this integrated control.

This study proposes a simulation model for electrohydraulic servosystem and investigates its pressure and flow responses. A mathematical model of this servosystem is proposed based on the force balance, voltage, and flow equations. Moreover, the stability of electrohydraulic servosystem is studied using the Bode plot and the Nichols diagram.

In this paper, using AMESIM, discretion of outlet pressure vs. displacement curve leads to a series of data. The outlet displacement parameters were set by data input via the prescribed route. The main valve, which is indeed a combination of multi-link three-position, six-way valve, is subdivided into several basic functional units, and modules of these units were established using corresponding modules in the hydraulic element database: BAO21 and BAO22 modules were used for the main body of slide valve, BAP12 module was used for the pilot control chamber, MAS005 module was used to characterize the mass of spool and the viscous friction experienced by spool, LSTP00A and MCLSPL00AA spring modules were used to establish the center spring.

The scheme of the control system used in this study is shown in Fig. 1a, where 1 is arm cylinder, 2 is electrohydraulic servovalve, 3 is main platform, 4 is valve pump, 5 is rotary motor, 6 is boom cylinder, and 7 is bucket. Photos of pressure/temperature sensors and data acquisition system are presented in Fig.1b and 1c, respectively.

The input electrical signal is amplified and transduced to the electrohydraulic servovalve, the spool shifts, the hydraulic pump initiates, resulting in displacement of the hydraulic cylinder. The output signal is then transduced to by the displacement sensor a feedback electrical signal, which is then compared to the command signal to obtain the bias 


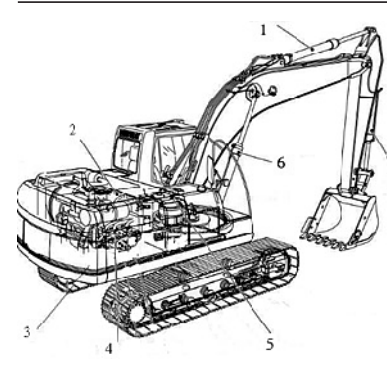

a

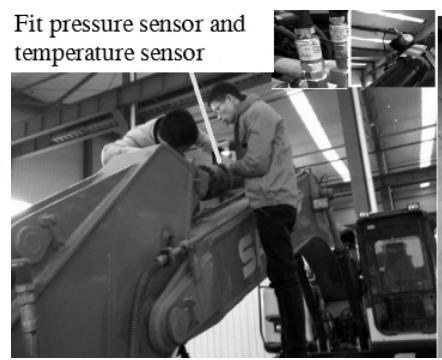

b

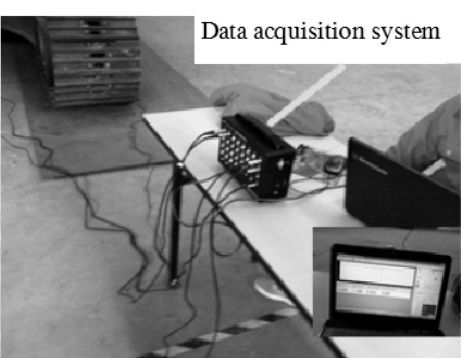

c

Fig. 1. Excavator structure diagram.

voltage signal. The latter is transmitted to the servovalve via the amplifier. The servovalve then controls the hydraulic actuator to reduce the bias between the output and command signals within a preset range $[4,5]$. In this way, a closed-loop control is achieved.

The composition of electrohydraulic servocontrol system is shown in Fig. 2, where 1 is valve pump, 2 is one-way valve, 3 is overflow valve, 4 is electrohydraulic servovalve, 5 is hydraulic bucket cylinder, 6 is displacement sensor, 7 is load, and 8 is servoamplifier).

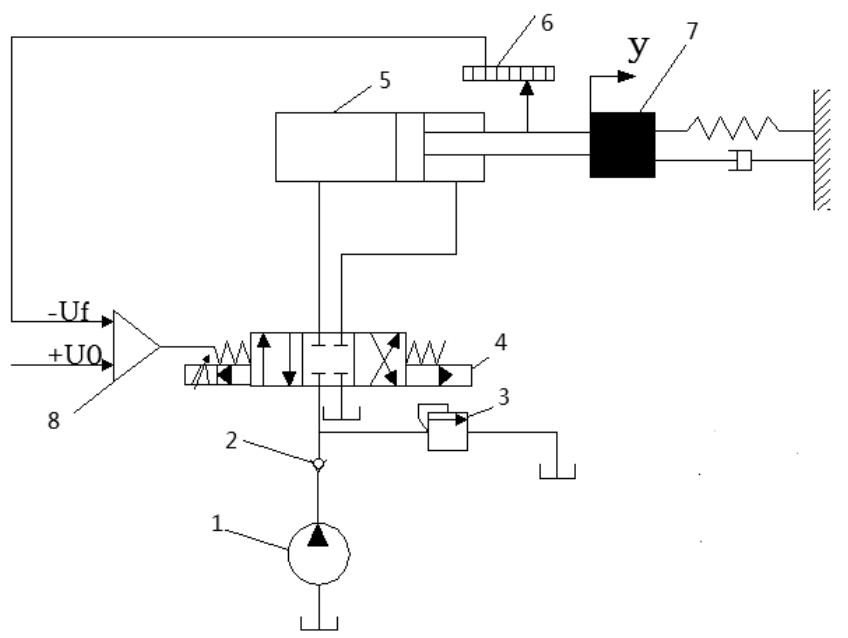

Fig. 2. Schematic structure of excavator.

\section{Mathematical Model of Electrohydraulic Servosystem.}

1.1. Servoamplifier. The bias control signal $(\Delta u)$ was generated by the comparison element based on input and feed-back signals. As the amplification element, the servo amplifier amplifies $\Delta u$, which is relatively weak, to realize the control of the electrohydraulic servovalve $[6,7]$. The transfer function is as follows:

$$
I(s)=K_{1} U(s)
$$

where $I$ is the input current to the electrohydraulic servovalve, $U$ is the voltage signal generated by the servo amplifier, and $K_{1}$ is the amplification coefficient.

1.2. Electrohydraulic servovalve. A displacement feedback servovalve consists of a moving coil force motor, control slide valve, and main valve. With current flowing through, the coil in the motor generates an electromagnetic force to push the control slide valve, the 
top and bottom throttle shifts, and the main valve shifts. Once the displacement of the control slide valve and that of the main spool are aligned, the valve does not move further.

1.3. Moving Coil Force Motor. The signal voltage on the control coil by the servo amplifier is the sum of the voltage drop on the resistor, self-induced back electromotive force in the control coil, and the back electromotive force induced by movement of control coil in the magnetic field. The voltage balance equation is as follows:

$$
E=\left(R_{c}+r_{p}\right) i+L_{c} d t_{c} / d t+K_{b} d x / d t
$$

where $R_{c}$ is the resistance of the control coil, $r_{p}$ is the internal resistance of the amplifier, $L_{c}$ is the inductance of the control coil, and $K_{b}$ is the back electromotive force constant $\left(K_{b}=B_{g} \pi D d N_{c}\right)$.

The force balance equation for coil component is as follows:

$$
F=m d^{2} x / d t^{2}+B d x / d t+K x,
$$

where $m$ is the mass of coil, $B$ is the damping coefficient of coil, and $K$ is the spring stiffness.

Laplace transform of Eqs. (2) and (3) results in

$$
I_{c}=\left(K_{1} U-K_{b} S X\right) /\left(\left(R_{c}-r_{p}\right)\left(1+s / \varpi_{\alpha}\right)\right),
$$

where $\varpi_{\alpha}$ is the corner frequency of the control coil $\left(\varpi_{\alpha}=\left(R_{c}+r_{p}\right) / L_{c}\right) \delta_{0}=B / 2 \sqrt{1 / k m}$, $\varpi_{0}=\sqrt{k / m}$,

$$
X / I_{c}=\left(K_{t} / K\right) /\left(s^{2} / \varpi_{0}^{2}+2 \delta_{0} / \varpi_{0} s+1\right)
$$

1.4. Control Slide Valve - Main Valve. The masses of front slide valve and main valve are $m_{1}$ and $m_{2}$ the dynamic damping coefficients of front slide valve and main valve are $c_{1}$ and $c_{2}$, the spring stiffness of front slide valve and main valve are $K_{a}$ and $K_{b}$, and the flow gain of front slide valve is $K_{q p}$. The force balance equation for front slide valve and main valve is as follows:

$$
\begin{gathered}
F_{1}=m_{1} d^{2} x / d t^{2}+c_{1} d x / d t+K_{q p} x_{v}, \\
F_{2}=m_{2} d^{2} x_{v} / d t^{2}+c_{2} d x_{v} / d t+K_{b} x_{v}-\Delta P_{x} A_{v} .
\end{gathered}
$$

The open capacity of front slide valve can be determined by

$$
x_{e}=x-x_{v} .
$$

Excluding the effects of flow force, the transfer function can be obtained based on Eqs. (6)-(8):

$$
\begin{gathered}
x_{v} / x_{e}=\left(K_{q p} / A_{v}\right) /\left(s\left(s^{2} / \omega_{h p}^{2}+2 s \delta_{h p} / \omega_{h p}+1\right)\right), \\
x_{v} / x=1 /\left(\left(s / K_{v}+1\right)\left(s^{2} / \omega_{h p}^{2}+2 s \delta_{h p} / \omega_{h p}+1\right)\right) .
\end{gathered}
$$

The simplified block diagram of transfer equation of direct location feedback servovalve is shown in Fig. 3. 


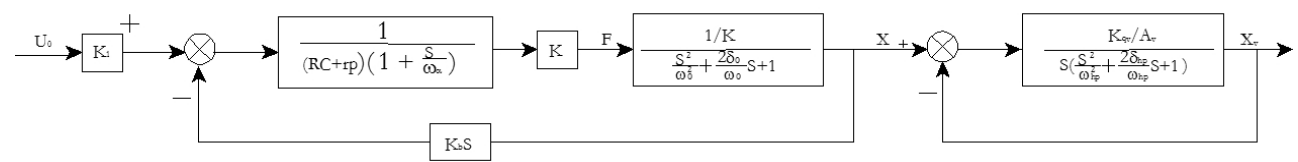

Fig. 3. Diagram of transfer equation of direct location feed-back servovalve.

Hydraulic Cylinder - Load. Assuming that the pressure in the hydraulic cylinder is uniform, the temperature and bulk modulus of hydraulic medium are constant and the leakage of hydraulic cylinder is laminar flow. The flow equation of electrohydraulic servovalve is as follows:

$$
Q_{L}=K_{q} x_{v}-K_{c} p_{L}
$$

If the piston is located in the middle part, the system stability is poor, the frequency of hydraulic component is low, and the damping ratio is low. Also, $V_{1}=V_{2}=V_{t} / 2$ is valid in the hydraulic cylinder. The overall leakage coefficient $\left(C_{t p}=C_{i p}+C_{e p} / 2\right)$ is used to reflect the effect of hydraulic cylinder leakage on the load flow. The flow in the hydraulic cylinder can be determined by

$$
Q_{L}=A_{p} d x_{p} / d t-C_{t p} p_{L}+v_{t} / 4 \beta \cdot d p_{t} / d t,
$$

where $A_{p}$ is the effective area of the piston $\left(\mathrm{m}^{2}\right), x_{p}$ is the displacement of the piston $(\mathrm{m})$, $C_{i p}$ is the leakage coefficient of the hydraulic cylinder $\left(\mathrm{m}^{3} \cdot \mathrm{s}^{-1} / \mathrm{Pa}\right)$, and $\beta$ is the effective bulk modulus $(\mathrm{Pa})$.

The force balance equation for hydraulic cylinder is as follows:

$$
A_{p} Q_{L}=m_{t} d^{2} x_{p} / d t^{2}-B d x_{p} / d t+K x_{p}+F_{L},
$$

where $m_{t}$ is the overall mass of piston $(\mathrm{kg}), F_{L}$ is the external load on the piston $(\mathrm{N})$, and $K_{c e}$ is the overall flow-pressure coefficient, $K_{c e}=K_{c}+C_{t p}$.

Equations (11)-(13) are equations for displacement, pressure, and flow of the hydraulic cylinder, respectively. These parameters are indicators of dynamic performance of the hydraulic cylinder. Laplace transform of these equations results in overall displacement of the piston in the hydraulic cylinder:

$$
\begin{aligned}
x_{p} & =\left(K_{q} / A_{p} x_{v}-K_{c e} / A_{p}^{2}\left(1+s V_{t} /\left(4 \beta K_{c e}\right) F_{L}\right)\right) /\left(m_{t} V_{t}\right)\left(4 \beta A_{p}^{2} s^{3}+\left(\left(m_{t} K_{c e}\right) / A_{p}^{2}+\right.\right. \\
& \left.\left.+\left(B V_{t}\right) /\left(4 \beta A_{p}^{2}\right)\right) s^{2}+\left(\left(\left(B K_{c e}\right) / A_{p}^{2}\right)+\left(K V_{t}\right) /\left(4 \beta A_{p}^{2}\right)+1\right)+K K_{c e} / A_{p}^{2}\right) .
\end{aligned}
$$

\section{Modeling of Electrohydraulic Servosystem.}

2.1. Establish System Modeling. In the electrohydraulic servo [8-11], the hydraulic cylinder pushes the load, the displacement sensor at the load converts location signal to electrical signal. The bias between the actual location signal and the designated location signal is amplified and applied on the electrohydraulic servovalve. The servo spool shifts, the flow of hydraulic system fluctuates, and the location of hydraulic cylinder is adjusted to achieve trajectory tracking.

The flow is defined as 0 when the servovalve is at the initial position. The flow is defined as +1 at an extreme position. Herein, Port $\mathrm{P}$ is connected to Port $\mathrm{A}$ and Port $\mathrm{T}$ is connected to Port B. The flow is defined as -1 at the other extreme position. Herein, Port A is connected to Port $\mathrm{T}$ and Port $\mathrm{B}$ is connected to Port $\mathrm{P}$. 
2.2. Step Signal Comparison. The key component parameters of the simulation model are summarized in Table 1. The values of these parameters were determined based on the actual system. The signal set-up of the signal source: the signal stays at 0 in $0 \sim 1 \mathrm{~s}$, increased to 0.8 in $1 \sim 4 \mathrm{~s}$, and stays at 0.8 in $4 \sim 6 \mathrm{~s}$. To test the dynamic characteristics of the system, typical step signals were employed as standard displacement signals. The reference value of step signal was set to be $0.1 \mathrm{~m}$. Figure 4 shows step signal displacement curves obtained by traditional control system and servo control system, respectively.

$\mathrm{T}$ a b 1 e 1

\section{System Parameters}

\begin{tabular}{|l|c|}
\hline Motor rated speed $(\mathrm{rpm})$ & 1500 \\
\hline Pump rated displacement $\left(\mathrm{cm}^{3} / \mathrm{rev}\right)$ & 122 \\
\hline Pump speed $(\mathrm{rpm})$ & 1500 \\
\hline Rated current of servovalve $(\mathrm{mA})$ & 200 \\
\hline Natural frequency $(\mathrm{Hz})$ & 50 \\
\hline Damping ratio & 1 \\
\hline Servoamplifier gain & 250 \\
\hline Diameter of hydraulic cylinder piston $(\mathrm{mm})$ & 120 \\
\hline Diameter of hydraulic cylinder piston rod $(\mathrm{mm})$ & 85 \\
\hline Piston block mass $(\mathrm{kg})$ & 100 \\
\hline Cylinder stroke $(\mathrm{m})$ & 1 \\
\hline
\end{tabular}

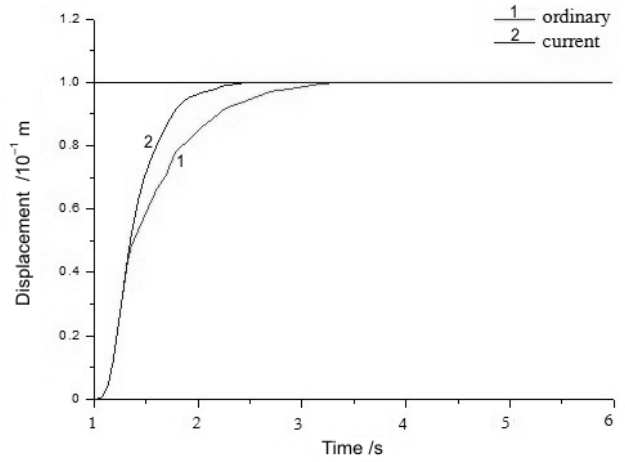

Fig. 4

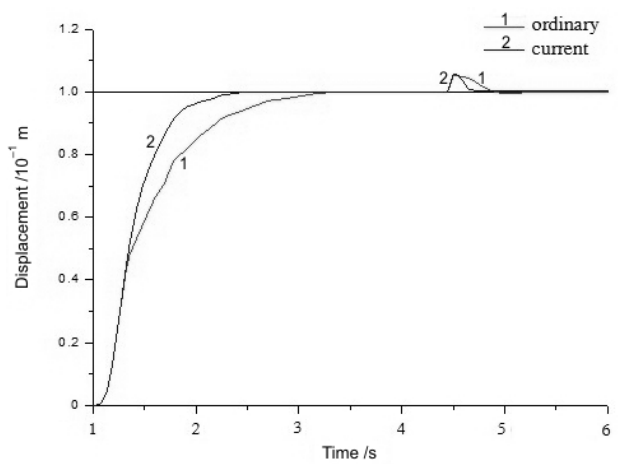

Fig. 5

Fig. 4. Displacement response curve of step signal.

Fig. 5. Displacement response curve of undesired signal.

As observed, the steady-state errors in both cases approached 0 , while the system rise durations were 1.96 and $1.59 \mathrm{~s}$, and the system stabilization durations were 3.36 and $2.41 \mathrm{~s}$. The rise duration and stabilization duration of output step signal decrease by 38 and $40.5 \%$, respectively, indicating improved output performance (fast response).

2.3. Anti-Interference Performance. To simulate excavator loading, non-restoring interference signals were involved. The interference signal, whose amplitude was $5 \%$ of signal amplitude, was added at $t=4.5 \mathrm{~s}$, as shown in Fig. 5.

As observed, the adjustment duration of the servosystem to interference signals was $0.32 \mathrm{~s}$, while that of traditional system was $1.6 \mathrm{~s}$ and fluctuations were observed. 
3. Performance Analysis of Servovalve Control Cylinder. Simulation and analysis of electrohydraulic servo. The simulation time is set to be $6 \mathrm{~s}$ to check the steady operation status of the system. The communication interval is set to be $0.01 \mathrm{~s}$ to exclude effects of system fluctuations. The pressure and flow of key components were obtained and analyzed.

Figure 6 shows the flow curve in the hydraulic cylinder. During $0 \sim 1 \mathrm{~s}$, the electrical signal is 0 , the servovalve is closed, and the flow in the hydraulic cylinder is 0 . After $1 \mathrm{~s}$, an electrical signal is observed, the servovalve shifts, and flows in rod-containing cavity and rodless cavity vary. At the initial stage, the flow in rod-containing cavity varies smoothly, while that in rodless cavity varies drastically. After $2.4 \mathrm{~s}$, fluctuations of flows in both cavities approach negligible. Eventually, the maximum flows in rodless cavity and rod-containing cavity are 8.66 and $4.33 \mathrm{l} / \mathrm{min}$, respectively. Figure 7 shows the pressure in the hydraulic cylinder.

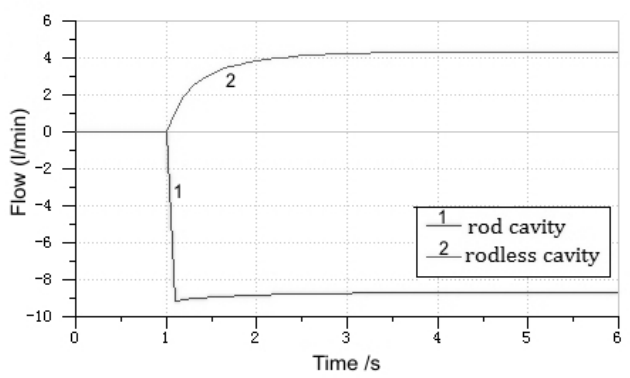

Fig. 6. Flow curve in the hydraulic cylinder.

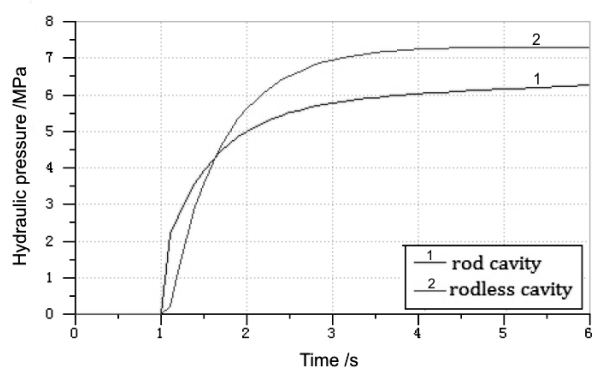

Fig. 7. Pressure in the hydraulic cylinder.

Figure 8 shows the displacement of servovalve spool as a function of time. Once the electrical signal is observed, the valve opens and reached the extreme position at $1.2 \mathrm{~s}$.

Figure 9 shows the flow curve at the pump valve outlet. Once the hydraulic system is initiated, the outlet flow is maintained at $183 \mathrm{l} / \mathrm{min}$. During $0 \sim 1 \mathrm{~s}$, the electrical signal is 0 and the flow at the overflow valve increases drastically to $183 \mathrm{l} / \mathrm{min}$. After $1 \mathrm{~s}$, an electrical signal is observed, the servovalve shifts, and the flow at the overflow valve decreases gradually. As the spool of servovalve reached the extreme position, the flow at the overflow valve stays at $174.3 \mathrm{l} / \mathrm{min}$.

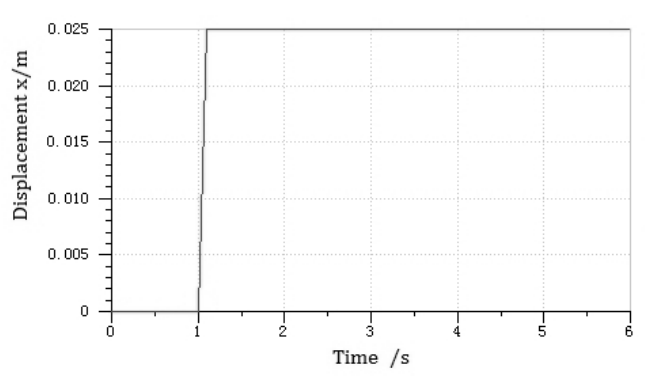

Fig. 8. Displacement of servovalve spool.

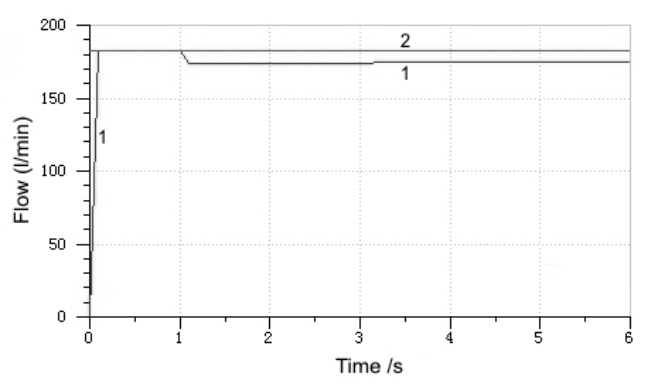

Fig. 9. Flow curve at the pump valve outlet: 1rod cavity, 2 -rodless cavity.

Conclusions. A mathematic model of the servosystem of valve-control excavator cylinder was established. With step signal and combination of step signal and impulse interference signal as the reference displacement signal, fast response capability, tracking capability, and anti-interference capability were studied. The results indicated that the rising and stabilization periods decreased by 38 and $40.5 \%$, respectively, the delay tracking period 
dropped by $52.6 \%$, and excellent anti-interference was observed. Once the servosystem approached the steady state, the maximum pressure of rod cavity reached $7.28 \mathrm{MPa}$, while the maximum and outlet flows corresponded to 4.33 and $174.3 \mathrm{l} / \mathrm{min}$, respectively.

1. C. Liu, Z. Tang, X. Zhao, and Z. Pey, "The modeling and simulation study of hydraulic intelligent power system based on AMESim," in: Proc. of the Guidance, Navigation and Control Conference (CGNCC), 2014 IEEE Chinese (August 8-10, 2014, Yantai, China), IEEE (2014), DOI: 10.1109/CGNCC.2014.7007419.

2. Y. Ye, C. B. Yin,Y. Gong, and J. J. Zhou, "Position control of nonlinear hydraulic system using an improved PSO based PID controller," Mech. Syst. Signal Pr., 83, 241-259 (2017).

3. W. Jia, C. Yin, D. Zhu, and X. Jiang, "Influence of rectangular grooved labyrinth seal on the flow characteristics of valve core," J. Comput. Theor. Nanos., 13, No. 4, 2376-2381 (2016).

4. N. Xie, X. Chen, and J. J. Guo, "Simulation analysis of proportional valve controlled cylinder hydraulic system based on AMESim," Adv. Mater.s Res., 668, 420-425 (2013).

5. W. Jia, C. Yin, B. Jia, et al., "Application research on the dual-spool valve control system in a hydraulic farm-oriented load tractor," INMATEH - Agricult. Eng., 48, No. 1, 103-112 (2016).

6. R. Amirante, L. A. Catalano, and P. Tamburrano, "The importance of a full 3D fluid dynamic analysis to evaluate the flow forces in a hydraulic directional proportional valve," Eng. Computation., 31, No. 5, 898-922 (2014).

7. L. L. Li, L. Q. Huo, Q. Zhang, and B. Sun, "Design and simulation analysis of servo amplifier," Process Automat. Instr., 33, No. 12, 83-85 (2012).

8. A. Tivay, M. Zareinejad, S. M. Rezaei, and K. Baghestan, "A switched energy saving position controller for variable-pressure electrohydraulic servosystems," ISA T., 53, No. 4, 1297-1306 (2014).

9. M. H. Chiang, L. W. Lee, and H. H. Liu, "Adaptive fuzzy controller with self-tuning fuzzy sliding-mode compensation for position control of an electrohydraulic displacement-controlled system," J. Intell. Fuzzy Syst., 26, No. 2, 815-830 (2014).

10. V. Milić, Z. Situm, and M. Essert, "Robust H-infinity position con trol synthesis of an electrohydraulic servosystem," ISA T., 49, No. 4, 535-542 (2010).

11. K. Baghestan, S. M. Rezaei, H. A. Talebi, and M. Zareinejad, "An energy-saving nonlinear position control strategy for electrohydraulic servosystems," ISA T., 59, 268-279 (2015).

Received 15. 09. 2017 